\title{
Do women who consult with naturopaths or herbalists have a healthy lifestyle?: a secondary analysis of the Australian longitudinal study on women's health
}

Amie Steel ${ }^{1 *}$ D, Stefania Tiveron ${ }^{2}$, Rebecca Reid ${ }^{1}$, Jon Wardle ${ }^{1}$, Holger Cramer $^{1,3}$, Jon Adams ${ }^{1}$, David Sibbritt ${ }^{1}$ and Romy Lauche ${ }^{1}$

\begin{abstract}
Background: Australians report consulting with a naturopaths or herbalists to improve their wellbeing, yet little is known about the associations between these consultations and the patients' health behaviours. This cross-sectional study aimed to examine the relationship between health behaviour and consultations with naturopaths or herbalists in three age cohorts of Australian women.

Methods: Women aged 19-25 years, 31-36 years, and 62-67 years from the Australian Longitudinal Study on Women's Health (ALSWH) were surveyed regarding smoking, alcohol or drug use, physical activity and dietary behaviour; and whether they consulted with naturopath/herbalists in the last 12 months. Associations were analysed using multivariable logistic regression.

Results: A total of 9151 (19-25 years), 8200 (31-36 years) and 11,344 (62-67 years) women were included in the analysis. Between 7.3 and $11.9 \%$ of women reported to have consulted with naturopaths/herbalists in the last 12 months. Women of all cohorts consulting with naturopath/herbalist were less likely to smoke (19-25 yrs.: Odds Ratio [OR] 0.61; 31-36 years: OR 0.58; 62-67 years: OR 0.29), more likely to report at least moderate levels of physical activity (19-25 yrs.: OR 1.41; 31-36 years: OR 1.34; 62-67 years: OR 1.34), and the use of vegetarian diets(19-25 yrs.: OR 1.40; 31-36 years: OR 1.77; 62-67 years: OR 2.28), compared to women not consulting with naturopaths/herbalists. Women consulting with naturopaths/herbalists however were also more likely to have used marijuana (19-25yrs: OR 1.18; 31-36 years: OR 1.42), or illicit drugs in the last 12 months (19-25 yrs.: OR 1.24; 31-36 years: OR 1.40).

Conclusions: Consultations with a naturopath or herbalist are associated with positive health behaviours that are protective of internationally important non-communicable diseases. Psychoactive drug use is also reported among women visiting a naturopath or herbalist. Further research is needed to understand the role naturopaths play in advising patients with regards to health and non-healthy behaviours.
\end{abstract}

Keywords: Health behaviours, Health promotion, Naturopathy, Illicit drugs, Dietary practices

\footnotetext{
*Correspondence: amie.steel@uts.edu.au

'Australian Research Centre in Complementary and Integrative Medicine (ARCCIM), Faculty of Health, University of Technology Sydney, Level 8, Bldg 10, 235-253 Jones St, Ultimo, NSW, Sydney, Australia

Full list of author information is available at the end of the article
}

(c) The Author(s). 2020 Open Access This article is licensed under a Creative Commons Attribution 4.0 International License, which permits use, sharing, adaptation, distribution and reproduction in any medium or format, as long as you give appropriate credit to the original author(s) and the source, provide a link to the Creative Commons licence, and indicate if changes were made. The images or other third party material in this article are included in the article's Creative Commons licence, unless indicated otherwise in a credit line to the material. If material is not included in the article's Creative Commons licence and your intended use is not permitted by statutory regulation or exceeds the permitted use, you will need to obtain permission directly from the copyright holder. To view a copy of this licence, visit http://creativecommons.org/licenses/by/4.0/ The Creative Commons Public Domain Dedication waiver (http://creativecommons.org/publicdomain/zero/1.0/) applies to the data made available in this article, unless otherwise stated in a credit line to the data. 


\section{Background}

Naturopathy is a traditional system of medicine which originates from Europe but is now practiced in over 80 countries across every world region [1]. The practice of naturopathy is defined by core principles and underpinned by philosophies which emphasise preventive medicine and patient education [2]. Naturopathic training varies based on the regulatory framework of the country it is practiced, but most commonly includes diet and lifestyle counselling followed by herbal medicine and clinical nutrition [3]. Naturopathy has also been argued to align with public health principles [4] and naturopaths in some countries are considered to be trained as primary care practitioners [5]. Naturopaths also treat diverse populations with varied health conditions and across all age groups [6]. Their consultations may include discussion of numerous health topics [6], and a strong focus on health behaviour change [7]. Individuals consulting with a naturopath have described positive experiences of practitioner empathy and qualities of patient-centred care including empowerment and support for lifestyle and behaviour change [8, 9]. In Australia, the naturopathic profession has been closely tied to Western herbal medicine, with the peak professional and regulatory bodies for naturopathy also representing herbalists $[10,11]$. Approximately $6.2 \%$ of Australians have consulted with a naturopath and 3.8\% have visited a herbalist in the previous 12 months and over half of those are consulting with a naturopath or herbalist to improve their well-being [12].

A number of factors characterise individuals that use complementary medicine (CM) services [13, 14] and may impact on the overall outcomes of care provided by a naturopath or Western herbalist [15]. For example, psychosocial factors such as spirituality and holistic belief systems are linked to complementary medicine (CM) use $[14,16,17]$. A mind-set which values a holistic approach is also compatible with having a higher internal health locus of control - a health belief that the outcome of one's health seeking is related to their own actions [18] - and as such a holistic belief system may influence the uptake and maintenance of self-care health behaviours. Equally, research has shown that health-aware behaviours and dissatisfaction with conventional medicine are strong predictors of CM health services [13].

In the context of the global burden of disease resulting from chronic illness, factors that influence both positive and risky health behaviours warrant close attention. Dietary choices, physical activity, alcohol consumption, and tobacco smoking impact significantly on the risk of non-communicable diseases [19-25] that are not only of international importance [26], but also seen as a priority at a national level by countries like Australia [27]. A strong focus of strategies aimed at addressing these diseases is to improve the delivery of primary health care and improve protective health behaviours in the community [27], including improving the delivery of integrated health care, diagnosis and treatment.

Despite the current knowledge regarding CM use and health behaviours, little is known about the health behaviours associated with consultations with specific health profession such as naturopaths and herbalists. Thus, the aim of this study was to analyse associations between health behaviours and visits with a naturopath or Western herbalist in a large nationally representative sample of Australian women.

\section{Methods}

This study presents analysis of data from the Australian Longitudinal Study on Women's Health (ALSWH) [28]. The ALSWH is a nationally representative study that was designed to assess health and wellbeing in Australian women [29]. The study was established in 1996 with three different age cohorts (1921-1926, 19461951, and 1973-1978 cohort) randomly selected from the national Medicare database [28]. In 2012 a new cohort was also introduced (1989-1995 cohort).

This study presents analysis of data from 9151 women from the 1946-1951 cohort (Survey 7, 2013; respondents aged 62-67 years), 8200 women from the 1973-1978 cohort (Survey 5, 2009; respondents aged 31-36 years), and 11,345 women from the 1989-1995 cohort (Survey 2, 2014; respondents aged 19-25 years). These datasets were chosen for the analysis as they provided the largest number of outcomes relevant to our research question.

\section{Consultation with naturopaths/herbalists}

The women were asked if they had consulted with a naturopath/herbalist in the past 12 months on a yes/no basis.

\section{Smoking}

Survey items were included that enquired about whether women were smoking cigarettes or tobacco products, or whether they had smoked in the past. Women who reported to currently smoke were asked to provide details about the frequency and quantity.

\section{Alcohol use}

A series of survey items reporting frequency and amount of alcohol consumption were also included in the analysis.

\section{Marijuana use}

Women in the 1973-1978, as well as the 1989-1995 cohorts were asked whether they had used marijuana (Cannabis, hash, grass, dope, pot, yandi) for non-medicinal 
purposes. Their response options were: never, more than 12 months ago, in the last 12 months.

\section{Illicit drug use}

Survey items that captured whether women they had used illicit drugs (Amphetamines, LSD, natural hallucinogens, tranquilizers, cocaine, ecstasy, inhalants, heroin or barbiturates) for non-medicinal purposes were used from the surveys admininstered to the 1973-1978 and 1989-1989 cohorts. Respondents could choose between never, more than 12 months ago, in the last 12 months.

\section{Physical activity}

A series of survey items examined physical activity by determining the type of activity (walking, moderate, vigorous activities), and frequency/duration of the activity within the past week.

\section{Dietary behaviour}

The Dietary Questionnaire for Epidemiological Studies Version 2, a 101-item food frequency questionnaire (FFQ) [30, 31] was included in the surveys used for this analysis and provided the data for examining respondents' dietary behaviour.

\section{Statistical analyses}

The data was initially recoded to enable the analysis needed to answer the research question. A binary variable was generated for smoking in which those who smoke regularly (on a weekly/daily basis]) were grouped separately to those who do not (including non-smokers, and occasional smokers). Alcohol use was recoded according to the National Health and Medical Research Council (NHMRC) classification [32], and recoded for the comparisons of those with high risk drinking behaviour (including risky drinkers, and high risk drinkers) vs. those without (including non-drinkers, low risk drinkers). Variables were created that compared women reporting Marijuana use in the past 12 months with those who did not. A similar variable was generated for illicit drugs use. Responses to the physical activity survey items were converted to metabolic equivalents (MET), with one MET equivalent to $3.5 \mathrm{~mL}$ of oxygen uptake per $\mathrm{kg}$ per minute. Based on their MET level women were classified as sedentary (0-33.2), low active (33.3-499), moderate (500-999) or high active $(\geq 1000)$. The recoding followed the guidelines from the Active Australia physical activity survey [29]. Based on the survey items reporting the the frequencies of food items consumed as part of respondents' usual eating habits in the past 12 months, women were classified as following a full-time vegetarian diet (no meat, no poultry), a vegan diet (no animal products including meat, poultry, eggs, dairy products of any kind), or an other diet. For the analysis, those following a vegetarian or vegan diet were compared to those who do not.

Analyses were conducted separately for the three age cohorts. Separate logistic regressions were conducted to determine whether smoking, alcohol, marijuana, or illicit drug use, physical activity and vegetarian diet were associated with the consulting with naturopaths/herbalists. Adjusted odds ratios with 95\% confidence intervals were computed for the independent variable. Analyses were adjusted for socio-demographic characteristics and confounding variables (socioeconomic status including marital status, education, income, area of residence, body mass index, and self-reported doctor diagnosed depression). Statistical significance was set at $p<0.05$. All statistical analyses were performed using IBM SPSS ${ }^{\odot}$ software (IBM SPSS Statistics for Windows, release 22.0. Armonk, NY: IBM Corp.).

\section{Results}

The prevalence of consulting with naturopaths/herbalists in each cohort can be found in Table 1. Highest prevalence of naturopath/herbalist consultations can be found in the 1973-1978 cohort (11.9\%), followed by the 1989-1995 cohort (8.6\%) and the 1946-1951 cohort (7.3\%). Alcohol was consumed by the vast majority of women, however only a minority showed high risk or risky drinking behaviour, with lower prevalence in the younger cohort. A substantial proportion of women, especially in the 1989-1995 cohort, reported having used marijuana in the past 12 months $(28.8 \%)$ compared to only $9.2 \%$ in the $1973-1978$ cohort. Most women in the cohorts were physically active with the oldest and youngest cohorts showing highest prevalence for at least moderate physical activity levels. Vegetarian dietary choices were however only reported by a minority of the older cohorts, and only in the 1989-1995 cohort was a substantial prevalence found.

Table 2 shows the associations between health behaviours and naturopath/herbalist consultations. Women in all three cohorts were less likely to smoke (Odds Ratio OR: 0.29 [0.15-0.56], 0.58 [0.44-0.75], $0.61[0.39-0.95]$, from the oldest to youngest age groups respectively) when they consulted with naturopaths/herbalist, compared to those who did not. Women consulting with naturopaths/herbalists were more likely to report at least moderate levels of physical activity (OR: 1.34 [1.10-1.62; 1.16-1.55], 1.41 [1.20-1.65], from the oldest to youngest age groups respectively), and report vegetarian/vegan dietary practices (OR: 1.40 [1.13-1.74], 1.77 [1.30-2.41], 2.28 [1.47-3.52], from the oldest to youngest age groups respectively), compared to women not consulting with naturopaths/herbalists. On the other hand, compared to women not consulting with naturopaths/herbalists, 
Table 1 Frequency of health behaviours in 9151 Australian women aged 62-67 years (1946-1951 Cohort), 8200 Australian women aged 31-36 years (1973-1978 Cohort), and 11,344 Australian women aged 19-25 years (1989-1995 Cohort), in \% of all women in the respective cohort. ${ }^{\mathrm{NA}}=$ Not assessed

\begin{tabular}{|c|c|c|c|}
\hline Variable & $\begin{array}{l}\text { 1946-1951 } \\
\text { Cohort }\end{array}$ & $\begin{array}{l}1973-1978 \\
\text { Cohort }\end{array}$ & $\begin{array}{l}\text { 1989-1995 } \\
\text { Cohort }\end{array}$ \\
\hline Consulting with naturopath/herbalist & 7.3 & 11.9 & 8.6 \\
\hline Smoking ( $\geq$ weekly) & 4.8 & 12.1 & 3.8 \\
\hline Alcohol use (high risk/risky drinking) & 6.0 & 4.4 & 2.9 \\
\hline Marijuana use (last 12 months) & NA & 9.2 & 28.8 \\
\hline Illicit drug use (last 12 months) & NA & 6.1 & 16.5 \\
\hline Physically active ( $\geq$ moderate) & 61.5 & 49.8 & 68.8 \\
\hline Vegetarian/vegan diet & 2.0 & 3.8 & 8.7 \\
\hline
\end{tabular}

women who did were also more likely to report higher likelihoods of marijuana use (OR: 1.18 [1.021.37], 1.42 [1.14-1.78], from the oldest to youngest age groups respectively), or illicit drug use in the last 12 months (OR: 1.24 \{1.05-1.48], 1.40 [1.07-1.83], from the oldest to youngest age groups respectively). The patterns of associations were similar across all cohorts of women.

\section{Discussion}

This article represents the first report from a nationally representative sample of women which examines the associations between consulting with a naturopath or herbalist and their health behaviours. The results suggest that women from all three cohorts exhibit differences in lifestyle behaviours associated with consultations with a naturopath or herbalist. Naturopathic principles include

Table 2 Output from the logistic regression models showing the association between consulting with a naturopath/herbalist and several health behaviour categories, in 9151 Australian women aged 62-67 years (1946-1951 Cohort), 8200 Australian women aged 31-36 years (1973-1978 Cohort), and 11,344 Australian women aged 19-25 years (1989-1995 Cohort). OR: Odds Ratio; Cl: Confidence interval. Confounder included in the analysis: Body mass index, depression, marital status, income management, area, education

\begin{tabular}{|c|c|c|c|c|c|c|}
\hline \multirow[t]{3}{*}{ Health behaviours } & \multicolumn{6}{|c|}{$\begin{array}{l}\text { Likelihood of health behaviours among women consulting with a naturopath/herbalist } \\
\text { compared to women who do not consult with a naturopath/herbalist }\end{array}$} \\
\hline & \multicolumn{2}{|c|}{ 1946-1951 Cohort } & \multicolumn{2}{|c|}{ 1973-1978 Cohort } & \multicolumn{2}{|c|}{ 1989-1995 Cohort } \\
\hline & $\begin{array}{l}\text { Odds ratio } \\
(95 \% \mathrm{Cl})\end{array}$ & $p$ & $\begin{array}{l}\text { Odds ratio } \\
(95 \% \mathrm{Cl})\end{array}$ & $p$ & $\begin{array}{l}\text { Odds ratio } \\
(95 \% \mathrm{Cl})\end{array}$ & $p$ \\
\hline \multicolumn{7}{|l|}{ Smoking } \\
\hline Not smoking or irregular smoking ( $\leq$ weekly) & ref & - & ref & & ref & \\
\hline Smoking regularly ( $\geq$ weekly) & $0.29(0.15,0.56)$ & $<0.001$ & $0.58(0.44,0.75)$ & $<0.001$ & $0.61(0.39,0.95)$ & 0.028 \\
\hline \multicolumn{7}{|l|}{ Alcohol use } \\
\hline \multicolumn{7}{|l|}{ No risk/low risk } \\
\hline High risk/risky & $0.74(0.49,1.11)$ & 0.144 & $0.77(0.54,1.11)$ & 0.163 & $0.72(0.45,1.14)$ & 0.162 \\
\hline \multicolumn{7}{|l|}{ Marijuana use } \\
\hline Did not use in the last 12 months & Ref & & Ref & & Ref & \\
\hline Used in the last 12 months & & & $1.42(1.14,1.78)$ & 0.002 & $1.18(1.02,1.37)$ & 0.029 \\
\hline \multicolumn{7}{|l|}{ Illicit drug use } \\
\hline Did not use in the last 12 months & - & - & Ref & & Ref & \\
\hline Used in the last 12 months & - & - & $1.40(1.07,1.83)$ & 0.013 & $1.24(1.05,1.48)$ & 0.014 \\
\hline \multicolumn{7}{|l|}{ Physical activity } \\
\hline Low/sedentary & ref & & ref & & ref & \\
\hline Moderate & $1.34(1.10,1.62)$ & 0.003 & $1.34(1.16,1.55)$ & $<0.001$ & $1.41(1.20,1.65)$ & $<0.001$ \\
\hline \multicolumn{7}{|l|}{ Vegetarian diet } \\
\hline Not vegetarian/vegan & ref & & ref & & ref & \\
\hline Vegetarian/vegan & $2.28(1.47,3.52)$ & $<0.001$ & $1.77(1.30,2.41)$ & $<0.001$ & $1.40(1.13,1.74)$ & 0.002 \\
\hline
\end{tabular}


a strong focus on educating individuals to modify their health behaviours to improve their health status [2]. Patients consulting with a naturopath have also reported empowerment as a feature of the naturopathic consultation $[8,9]$ while clinical research has highlighted the emphasis placed on modifying dietary and lifestyle behaviours within the naturopathic system of healing [15]. Equally, individuals that choose to consult with a naturopath may be predisposed to specific health behaviours due to their own individual holistic personal belief systems $[14,16,17]$. It is unknown whether consulting with a naturopath/herbalist empowers women to adopt the health behaviours discussed in this article, or if personal characteristics and psychosocial factors driving these health behaviours also predict intention and openness to seek naturopathic/herbalist care. Given that health aware behaviours are subject to interpretation based on one's values, beliefs and philosophical orientations towards health, consulting with a naturopath/herbalist may align with a similar belief system. However, the directionality of the relationship between health behaviors and consultation with a naturopath can not be confirmed due to the cross-sectional nature of the study.

Women consulting with naturopaths/herbalists were more likely to report engaging in positive health behaviours such as not smoking, at least moderate levels of physical activity, and following a vegetarian or vegan diet. These health behaviours are known to reduce the risk of diseases that contribute a significant burden on contemporary health systems such as cardiovascular disease [19-21], metabolic syndrome [22, 23], cancer [19, $21]$, and mental illness [24, 25]. Within the context of cardiovascular disease, a 2011 finding that the risk attributable to coronary heart disease from smoking is greater in women compared to men [20] becomes particularly important given Australian women are more likely than men to consult with a naturopath or herbalist [12]. In this context, if naturopaths or herbalists are engaged in lifestyle counselling which encourages smoking cessation [6], then these health professions may have a potential role in addressing smoking prevalence in female populations. Alternatively, if the decision to engage in these positive health behaviours is made prior to consultation with a naturopath or herbalist then the users' view of naturopathy and herbal medicine within their wider approach to health warrants closer investigation. US research proposes different characteristics among CM users based on whether they access CM for health promotion or treatment [33]. With this in mind, it is possible that some individuals may follow these positive health behaviours before they choose to consult with a naturopath or herbalists, while others may engage in such behaviours as a result of the interaction with or advice from the naturopath or herbalist.
Alcohol was consumed by most of the women who consulted with a naturopath in our study, however only a minority showed high risk or risky drinking behaviour particularly in the younger cohort; and alcohol consumption was not associated with the (non-) consultation of naturopaths/herbalists. Previous research in the US has found CM users also have a higher incidence of consuming alcohol daily but not meeting the classification of heavy drinking [34]. Other research elsewhere also found alcohol consumption was not a significant predictor of CM use $[35,36]$. The health impacts of alcohol consumption have received increased interest among public health researchers in recent years in light of conflicting findings regarding the potential risk and benefits associated with 'moderate' compared with 'heavy' alcohol use or abstinence [37]. While some groups argue that the beneficial effects attributed to alcohol consumption may differ based on the type of alcohol consumed [38], epidemiological meta-analyses indicate no positive health benefits to all-cause mortality for moderate alcohol use [39]. Within the context of naturopathy and herbal medicine users, while contemporary research indicates nine out of ten naturopaths in Australia 'sometimes' or 'often' discuss the alcohol use with their patients [6], little is known about the specific advice regarding alcohol consumption given to patients by clinicians irrespective of the changing consensus towards alcohol's health effects.

This study also reports a higher prevalence of marijuana use or illicit drug use in women who consult with naturopaths/herbalists, compared to those who do not. The apparent contrast between the prevalence of other positive health behaviours and the use of psychoactive drugs may be explained by previously reported perceptions of self-reported health benefits among drug users [40]. Over $80 \%$ of users also reported having had a 'spiritual experience' from a psychoactive drug [40]. Given the potential relationship between CM use and spiritual beliefs [41], a further exploration of the higher illicit drug use among users of naturopaths and herbalists may provide new insights into the role of psychoactive substances in spiritual practice for some individuals. An alternative explanation for the pattern of illicit drug use among users of naturopath and herbalist services is the potential for both behaviours (drug use and naturopath/herbalist consultations) to be part of an individual's counterculture lifestyle [42, 43]. Previous research also suggests the personality trait "openness to new experience" as a predictor of CM use in general, but specifically with the decision to initially try and explore CM [44], and this characteristic may also contribute to a decision to use marijuana [45]. Furthermore, some illicit drugs may be associated with perceived benefits that appeal to healthy individuals looking to enhance academic 
and work performance, especially stimulant medications such as amphetamine [46]. Irrespective of the reason for illicit drug use, this research emphasises the need for naturopaths and herbalists to be appropriately trained to enquire about illicit drug use and counsel behaviour change among individuals using illicit drugs. While many Australian naturopaths not only discuss substance use with their patients, approximately one third report 'sometimes' or 'often' treating drug and alcohol addiction [6]. However, as this is the first time to our knowledge that substance use behaviours among naturopathy or herbal medicine users has been reported, further research is needed to understand the dynamic between these health behaviours and this sub-population.

\section{Limitations}

The findings from this study should be considered in light of its limitations: naturopath/herbalist consultations were assessed as one item; therefore, it cannot be identified which practitioner was consulted. Furthermore, the data are based on self-reports and women may not have recollected all health behaviour details correctly, and a social desirability bias cannot be ruled out. Despite these limitations, the ALSWH is a comprehensive and wellrespected source for epidemiological data and the large number of participants as well as the inclusion of the most important confounders within the regression models provides strength to the analyses reported here.

\section{Conclusions}

There is a difference in health behaviours among women that consult with a naturopath or herbalist compared to women that do not, and these differences have important implications in public health policy and primary health service delivery. Naturopaths and herbalists may have an influential role in supporting positive health behaviours and counseling behaviour change among individuals identified as engaging in risky behaviours. The gaze of health research and policy needs to widen to encompass health professions such as naturopathy and herbal medicine and capitalise on their potential contribution to population health.

\section{Abbreviations \\ ALSWH: Australian Longitudinal Study on Women's Health; CM: Complementary medicine; DOHA: Department of Health and Ageing FFQ: Food frequency questionnaire; MET: Metabolic equivalents; NHMR C: National Health and Medical Research Council; OR: Odds ratio; US: United States}

\section{Acknowledgements}

The research on which this paper is based was conducted as part of the Australian Longitudinal Study on Women's Health (ALSWH), The University of Newcastle and The University of Queensland. We are grateful to the Australian Government Department of Health and Ageing (DOHA) for funding the ALSWH and to the women who provided the survey data. The authors also thank Professor Graham Giles of the Cancer Epidemiology Centre of Cancer Council Victoria, for permission to use the Dietary
Questionnaire for Epidemiological Studies (Version 2), Melbourne: Cancer Council Victoria, 1996.

\section{Authors' contributions}

$R L$ analysed the data. $R L, A S, R R$ and $S T$ contributed to interpreting the data and prepared the first draft of the manuscript. JW, JA, HC and DS provided substantial edits and revisions to the manuscript. All authors approved the submitted version.

\section{Funding}

The ALSWH is funded by the Australian Government Department of Health and Ageing (DOHA). The funding bodies played no role in the design of the study and collection, analysis, and interpretation of data and in writing the manuscript.

\section{Availability of data and materials}

The data that support the findings of this study are available from Women's Health Australia but restrictions apply to the availability of these data, which were used under license for the current study, and so are not publicly available. Data are however available from the authors upon reasonable request and with permission of Women's Health Australia.

Ethics approval and consent to participate

As this paper represents a secondary analysis of existing ALSWH data, no ethical clearance was required.

Consent for publication

Not applicable

\section{Competing interests}

$\mathrm{HC}$ is a Section Editor (Clinical Research) and AS, JW, JA and RL are Associate Editors for BMC Complementary Medicine and Therapies.

\section{Author details}

${ }^{1}$ Australian Research Centre in Complementary and Integrative Medicine (ARCCIM), Faculty of Health, University of Technology Sydney, Level 8, Bldg 10, 235-253 Jones St, Ultimo, NSW, Sydney, Australia. ${ }^{2}$ Sick Kitty Naturopathic Clinic, Ontario, Canada. ${ }^{3}$ Department of Internal and Integrative Medicine, Evang. Kliniken Essen-Mitte, Faculty of Medicine, University of Duisburg-Essen, 45276 Essen, Germany.

Received: 23 April 2020 Accepted: 10 November 2020 Published online: 18 November 2020

\section{References}

1. World Naturopathic Federation. Global naturopathic regulation. Toronto: World Naturopathic Federation; 2018.

2. World Naturopathic Federation. WNF white paper: naturopathic philosophies, principles and theories. Canada: World Naturopathic Federation; 2017.

3. World Naturopathic Federation. WNF - naturopathic roots report. Toronto: World Naturopathic Federation; 2016.

4. Wardle J, Oberg E. The intersecting paradigms of naturopathic medicine and public health: opportunities for naturopathic medicine. J Altern Complement Med. 2012;17(11):1079-84.

5. Fleming $\mathrm{S}$, Gutknecht N. Naturopathy and the primary care practice. Primary Care. 2010;37(1):119-36.

6. Steel A, Schloss J, Leach M, Adams J. The naturopathic profession in Australia: a secondary analysis of the Practitioner Research and Collaboration Initiative (PRACI). Complement Ther Clin Pract. 2020;40: 101220.

7. Steel A, Foley H, Bradley R, Van De Venter C, Lloyd I, Schloss J, Wardle J, Reid R. Overview of international naturopathic practice and patient characteristics: results from a cross-sectional study in 14 countries. BMC Complement Med Ther. 2020;20(1):59.

8. Foley $\mathrm{H}$, Steel A. Patient perceptions of patient-centred care, empathy and empowerment in complementary medicine clinical practice: a crosssectional study. Adv Integr Med. 2017:4:22-30.

9. Foley $\mathrm{H}$, Steel A, Adams J. Perceptions of person-centred care amongst individuals with chronic conditions who consult complementary medicine practitioners. Complement Ther Med. 2020:102518. 
10. Naturopaths and Herbalists Association of Australia. About the Naturopaths and Herbalists Association of Australia; 2020. http://www.nhaa.org.au/about. Accessed 16 Nov 2020.

11. Australian Register of Naturopaths and Herbalists. ARONAH Documents; 2020. http://www.aronah.org/aronah-documents/. Accessed 16 Nov 2020.

12. Mclntyre E, Adams J, Foley H, Harnett J, Leach MJ, Reid R, Schloss J, Steel A. Consultations with naturopaths and western herbalists: prevalence of use and characteristics of users in Australia. J Altern Complement Med. 2018;25(2).

13. Fouladbakhsh JM, Stommel M. Using the behavioral model for complementary and alternative medicine: the CAM healthcare model. J Complement Integr Med. 2007;4(1).

14. Bishop FL, Lewith GT. Who uses CAM? A narrative review of demographic characteristics and health factors associated with CAM use. eCAM. 2010;7(1):11-28.

15. Myers S, Vigar $V$. The state of the evidence for whole-system multi-modality naturopathic medicine: a systematic scoping review. J Altern Complement Med. 2019;25(2)

16. Astin J. Why patients use alternative medicine? Results of a national study. J Am Med Assoc. 1998;279:1548-53.

17. Reid R, Steel A, Wardle J, Trubody A, Adams J. Complementary medicine use by the Australian population: a critical mixed studies systematic review of utilisation, perceptions and factors associated with use. BMC Complement Altern Med. 2016;16(1):176.

18. Sasagawa M, Martzen MR, Kelleher WJ, Wenner CA. Positive correlation between the use of complementary and alternative medicine and internal health locus of control. Explore (New York, NY). 2008;4(1):38-41.

19. Dinu M, Abbate R, Gensini GF, Casini A, Sofi F. Vegetarian, vegan diets and multiple health outcomes: a systematic review with meta-analysis of observational studies. Crit Rev Food Sci Nutr. 2017;57(17):3640-9.

20. Huxley RR, Woodward M. Cigarette smoking as a risk factor for coronary heart disease in women compared with men: a systematic review and meta-analysis of prospective cohort studies. Lancet. 2011;378(9799):1297-305.

21. Kyu HH, Bachman VF, Alexander LT, Mumford JE, Afshin A, Estep K, Veerman $J$, Delwiche K, lannarone ML, Moyer ML. Physical activity and risk of breast cancer, colon cancer, diabetes, ischemic heart disease, and ischemic stroke events: systematic review and dose-response meta-analysis for the Global Burden of Disease Study 2013. Bmj. 2016;354:i3857.

22. Sun K, Liu J, Ning G. Active smoking and risk of metabolic syndrome: a meta-analysis of prospective studies. PLoS One. 2012;7(10):e47791.

23. Lee $Y$, Park K. Adherence to a vegetarian diet and diabetes risk: a systematic review and meta-analysis of observational studies. Nutrients. 2017;9(6):603.

24. Taylor G, McNeill A, Girling A, Farley A, Lindson-Hawley N, Aveyard P. Change in mental health after smoking cessation: systematic review and meta-analysis. Bmj. 2014;348:g1151.

25. Sofi F, Valecchi D, Bacci D, Abbate R, Gensini GF, Casini A, Macchi C. Physical activity and risk of cognitive decline: a meta-analysis of prospective studies. J Intern Med. 2011:269(1):107-17.

26. Benziger CP, Roth GA, Moran AE. The global burden of disease study and the preventable burden of NCD. Glob Heart. 2016;11(4):393-7.

27. Commonwealth of Australia. Inquiry into chronic disease prevention and management in primary health care. Canberra: House of Representatives Standing Committee on Health; 2016.

28. Brown WJ, Bryson L, Byles JE, Dobson AJ, Lee C, Mishra G, Schofield M. Women's health Australia: recruitment for a national longitudinal cohort study. Women Health. 1999;28(1):23-40.

29. Brown WJ, Burton NW, Marshall AL, Miller YD. Reliability and validity of a modified self-administered version of the active Australia physical activity survey in a sample of mid-age women. Aust N Z J Public Health. 2008;32(6):535-41.

30. Ireland P, Jolley D, Giles G, O'Dea K, Powles J, Rutishauser I, Wahlqvist M, Williams J. Development of the Melbourne FFQ: a food frequency questionnaire for use in an Australian prospective study involving an ethnically diverse cohort. Asia Pac J Clin Nutr. 1994:3(1):19.

31. Hodge A, Patterson AJ, Brown WJ, Ireland P, Giles G. The Anti Cancer Council of Victoria FFQ: relative validity of nutrient intakes compared with weighed food records in young to middle-aged women in a study of iron supplementation. Aust N Z J Public Health. 2000;24(6):576-83.

32. Holman CDAJ, English DR, Milne E, Winter MG. Meta-analysis of alcohol and all-cause mortality: a validation of NHMRC recommendations. Med J Aust. 1996;164(3):141-5.
33. Davis MA, West AN, Weeks WB, Sirovich BE. Health behaviors and utilization among users of complementary and alternative medicine for treatment versus health promotion. Health Serv Res. 2011;46(5):1402-16.

34. Nahin RL, Dahlhamer JM, Taylor BL, Barnes PM, Stussman BJ, Simile CM, Blackman MR, Chesney MA, Jackson M, Miller H, et al. Health behaviors and risk factors in those who use complementary and alternative medicine. BMC Public Health. 2007;7(1):217.

35. Burke A, Upchurch DM, Dye C, Chyu L. Acupuncture use in the United States: findings from the national health interview survey. J Altern Complement Med. 2006;12(7):639-48.

36. Ng TP, Tan C, Kua E. The use of Chinese herbal medicines and their correlates in Chinese older adults: the Singapore Chinese longitudinal aging study. Age Ageing. 2004;33(2):135-42

37. Costanzo S, de Gaetano G, Di Castelnuovo A, Djoussé L, Poli A, Van Velden D. Moderate alcohol consumption and lower total mortality risk: justified doubts or established facts? Nutrition, Metabolism and Cardiovascular Diseases; 2019.

38. Artero A, Artero A, Tarín JJ, Cano A. The impact of moderate wine consumption on health. Maturitas. 2015;80(1):3-13.

39. Stockwell T, Zhao J, Panwar S, Roemer A, Naimi T, Chikritzhs T. Do "moderate" drinkers have reduced mortality risk? A systematic review and meta-analysis of alcohol consumption and all-cause mortality. J Stud Alcohol Drugs. 2016;77(2):185-98.

40. Carhart-Harris RL, Nutt DJ. User perceptions of the benefits and harms of hallucinogenic drug use: a web-based questionnaire study. J Subst Abus. 2010;15(4):283-300.

41. Ellison CG, Bradshaw M, Roberts CA. Spiritual and religious identities predict the use of complementary and alternative medicine among US adults. Prev Med. 2012;54(1):9-12.

42. Jordan M. A dialogue between naturopathy and critical medical anthropology. Med Anthropol Q. 2012;26(2):292-8.

43. Sulkunen P. Between culture and nature: intoxication in cultural studies of alcohol and drug use. Contemp Drug Probl. 2002;29(2):253-76.

44. Sirois FM, Gick ML. An investigation of the health beliefs and motivations of complementary medicine clients. Soc Sci Med. 2002;55(6):1025-37.

45. Terracciano A, Löckenhoff CE, Crum RM, Bienvenu OJ, Costa PT Jr. Fivefactor model personality profiles of drug users. BMC Psychiatry. 2008;8:22.

46. Ilieva I, Farah M. Enhancement stimulants: perceived motivational and cognitive advantages. Front Neurosci. 2013;7(198).

\section{Publisher's Note}

Springer Nature remains neutral with regard to jurisdictional claims in published maps and institutional affiliations.

Ready to submit your research? Choose BMC and benefit from:

- fast, convenient online submission

- thorough peer review by experienced researchers in your field

- rapid publication on acceptance

- support for research data, including large and complex data types

- gold Open Access which fosters wider collaboration and increased citations

- maximum visibility for your research: over $100 \mathrm{M}$ website views per year

At $\mathrm{BMC}$, research is always in progress.

Learn more biomedcentral.com/submission 